\title{
Análise da liderança diretiva na formação de professores em Benguela, Angola
}

\section{Analysis of managerial leadership in teacher education in Benguela, Angola}

\author{
Pedro Victoria Salvador ${ }^{1}$, María Pilar Cáceres Reche ${ }^{2}$, Miriam Ágreda Montoro ${ }^{3}$ \\ ${ }^{1}$ Escola de Formação de Professores BG 4011, Benguela, Angola (psalvador115@gmail.com) \\ ${ }^{2}$ Departamento Didáctica y Organización Escolar, Universidad de Granada, España (caceres@ugr.es) \\ ${ }^{3}$ Departamento de Pedagogía, Universidad de Jaén, España (magreda @ujaen.es)
}

\section{RESUMO:}

$\mathrm{O}$ artigo resulta de um conjunto de considerações que tiveram origem na análise da liderança diretiva a partir da perceção dos professores das escolas do $2^{\circ}$ ciclo de formação de professores de Benguela, Angola, e por uma revisão bibliográfica que nos permitiu abordar conceitos visando aclarar a problemática da liderança das escolas. De acordo com os objetivos traçados para este estudo, optámos pelo enfoque metodológico misto ou descritivo, com um desenho não experimental, utilizando instrumentos de recolha de dados quantitativos. A constatação de que a escola é uma organização complexa que exige uma forte e boa liderança permitiu-nos perceber que só um estilo de liderança adequado a instituições educativas seria capaz de dar resposta às necessidades e objetivos da escola.

PALAVRAS CHAVE: LIDERANÇA, GESTÃO ESCOLAR, PESSOAL DIRIGENTE.

\begin{abstract}
:
This article aims at presenting the results from a set of considerations that originated from the analysis of the directive leadership from the perception of teachers in the second cycle of teacher training schools in Benguela, Angola, and by a bibliographic review that allowed us to discuss some relevant concepts aiming to clarify the problem of school leadership. Taking into account the objectives outlined for this research, we opted for a mixed methodological approach, with a non-experimental design, using quantitative data collection instruments. The realization that a school is a complex organization that requires strong and good leadership allowed us to understand that only a leadership style appropriate to educational institutions would be able to meet the school's needs and goals.
\end{abstract}

KEYWORDS: LEADERSHIP, SCHOOL MANAGEMENT, MANAGERIAL STAFF. 


\section{INTRODUCCIÓN}

A necessidade de as organizações, no caso particular as escolas, e as suas lideranças se adaptarem à exigente dinâmica atual foi o que mais contribuiu para engrossar o léxico pedagógico com os conceitos de liderança, desde há muito pertença naturalizada nas áreas política e empresarial.

Este trabalho, visa abordar os modos de atuação do diretor da escola no sentido de dar resposta às mudanças e à complexidade da organização da qual é líder.

A liderança diretiva joga um papel importante na melhoria das escolas e no processo de aprendizagem. Por isso é necessário conhecer os tipos de liderança exercidos pelos diretores das escolas de formação de professores de Benguela, Angola.

Segundo estudo Podsakoff, MacKenzie e Bommer (1996), focalizar a função dos diretores de escolas na liderança pedagógica, é uma estratégia para o êxito dos sistemas educativos.

A liderança exercida pelos diretores é uma das variáveis escolares que mais influencia no sucesso e êxito académico conjugado com o desempenho dos docentes em sala de aulas (Avolio, 1997; Marfán, Muñoz e Weinstein, 2012). Assim pois, a liderança para que se traduza em melhoria da qualidade e do desempenho a grande escala, tem de ser concebida como uma prática e não como um conjunto de atributos pessoais (Elmore, 2010). Um bom gestor não se traduz necessariamente em ser um bom líder de escola, é o caso de muitos/as diretores/as que são apenas bons gestores e brilhantes executivos. O líder dinamiza, motiva, arrasta o coletivo para a construção e reconstrução permanente de um projeto educativo.

Uma das principais tarefas da liderança é desenvolver mecanismos de interação e de influência interpessoal para dinamizar as pessoas e os grupos em uma determinada direção (Brugué, Gallego e Gonzales 2010; Lorenzo, Trujillo e Morales, 2008).

A visão, missão e objetivos claros, difundidos e conhecidos, que orientam o desenvolvimento organizacional e a estratégia de melhoria das escolas, deve ser função básica dos diretores, que orientam mediante práticas de liderança $o$ desenvolvimento organizacional e institucional da escola. Aspecto chave no acompanhamento e monitoramento da escola.

Constam nos maiores desafios de um líder os seguintes: definir a missão e o código de conduta da organização e comunicá-lo sistemática e congruentemente, em especial com o seu exemplo
(Sánchez e Rodríguez, 2010); estar presente, isto é, entrar em contacto e diálogo com os seres humanos que compõem a organização ou com ela se relacionam (Begoña et al., 2013; Hué, 2012; Roca, 2011).

A rede de relações entre diretores e docentes em uma escola, determina em grande medida o domínio e influência que possuem uns sobre outros. O poder constitui uma peça fundamental na compreensão do funcionamento das organizações, de maneira que se possa correlacionar o êxito com a realização de algumas atividades específicas, assim como o exercício oportuno e adequado do poder. Neste sentido, alguns dos atributos associados a liderança diretiva constam na tabela 1 .

Tabela 1. Atributos da liderança directiva (Lorenzo, 2004, p.193)

\begin{tabular}{|c|c|c|c|}
\hline $\begin{array}{l}\text { Consciência } \\
\text { de si mesmo }\end{array}$ & Autogestão & $\begin{array}{l}\text { Consciência } \\
\text { social }\end{array}$ & $\begin{array}{l}\text { Gestão } \\
\text { relações }\end{array}$ \\
\hline $\begin{array}{l}\text { Consciência } \\
\text { emocional de } \\
\text { si mesmo }\end{array}$ & Autocontrolo & Empatia & Inspiração \\
\hline \multirow{3}{*}{$\begin{array}{l}\text { Valorização } \\
\text { adequada de } \\
\text { si mesmo }\end{array}$} & Transparência & $\begin{array}{l}\text { Consciência } \\
\text { organizativa }\end{array}$ & Influência \\
\hline & Adaptabilidade & Serviço & $\begin{array}{l}\text { Desenvolvimento } \\
\text { pessoal dos demais }\end{array}$ \\
\hline & Sucesso & & Catalisar o câmbio \\
\hline \multirow[t]{2}{*}{$\begin{array}{l}\text { Confiança } \\
\text { em si mesmo }\end{array}$} & Iniciativa & & $\begin{array}{l}\text { Gestão } \\
\text { conflitos }\end{array}$ \\
\hline & Otimismo & & $\begin{array}{l}\text { Trabalho } \\
\text { equipa }\end{array}$ \\
\hline
\end{tabular}

A atitude, comportamento e práticas dos diretores devem estar orientados ao fortalecimento institucional, prevalecendo a prática sobre os atributos pessoais. Todavia, as atitudes e comportamentos dos líderes são percebidos pelos seguidores e para eles estes definem as características do líder e geram confiança. Contudo, o conhecimento profissional, as competências requeridas para o exercício da liderança, segundo a orientação da organização, requerem processo de formação permanente.

A formação dos líderes é um aspeto primordial e necessária para desenvolver com êxito suas funções.

Atualmente, a humanidade atravessa uma era de mudança, complexidade e incerteza, a todos níveis.

Os principais problemas que ocorrem no sector da educação nesta província são: o número reduzido de escolas, a fraca assiduidade e pontualidade de alguns professores, número elevado de candidatos que procuram pela formação, falta de meios didáticos e outros. Tais problemas comprometem o normal funcionamento das instituições educativas a nível da província. É, pois, neste contexto que a liderança emerge como elemento catalisador das organizações, podendo esta, de acordo a equipa 
diretiva que integra, conduzi-las com ou sem eficácia (Díaz e Martín, 2015).

De facto, a liderança e, nomeadamente a liderança diretiva, desempenha um papel fundamental na vida das escolas; uma alteração na liderança pode melhorar ou comprometer a sua imagem e função. Neste sentido, só com a prática de uma liderança eficaz e eficiente haverá um desenvolvimento e inovação nas organizações, em particular nos recursos humanos e na capacidade das pessoas estarem motivadas para o desempenho das suas funções (Dans Álvarez de Sotomayor e Muñoz, 2016; Gámez e Martín, 2016). Uma boa prática de direção e gestão de recursos humanos constitui a chave para alcançar a qualidade e sucesso da organização (País, Santos e Pedro, 2016).

A liderança surge como um processo de influência sobre as pessoas, no sentido das mesmas agirem no alcance da concretização dos objetivos de uma organização. Apresenta-se, então, como um processo que consiste em influenciar, persuadir e motivar o grupo, para que esta aja voluntariamente num determinado sentido e direção, definindo objetivos dinamizadores e mobilizadores de elementos capazes de concretizarem determinados propósitos.

Neste sentido, a presente investigação procura analisar de qué modo a prática da direção/liderança e gestão de recursos humanos está diretamente relacionada com o líder que conduz a vida de uma escola. O sucesso de uma instituição educativa depende do líder, do tipo de liderança exercida e da gestão adequada dos recursos humanos.

Assim, é imperioso o entendimento do constructo em análise, mais especificamente o modo como a liderança diretiva é exercida nas Escolas do $2^{\circ}$ Ciclo de Formação de Professores de Benguela. Face ao exposto enunciamos a seguinte pergunta de partida, no âmbito da nossa investigação:

Qual a perceção dos Professores sobre a liderança diretiva das Escolas do $2^{\circ}$ Ciclo de Formação de Professores de Benguela, Angola.

\section{MATERIAL Y MÉTODO}

\subsection{Objetivo}

Neste sentido, de acordo com a justificação teórica, se apresenta a necessidade de abordar a análise da liderança diretiva a partir da perceção dos professores das escolas do $2^{\circ}$ ciclo de formação de professores de Benguela, Angola.

A compreensão dos objetivos que cada estudo define a constitui de uma questão fulcral no desenho da investigação, principalmente, no que se refere à especificação das questões orientadoras. $\mathrm{Na}$ concretização deste estudo, o objetivo geral é, por nós formulado, do seguinte modo: Conhecer os estilos de liderança diretiva a partir da perceção dos professores das Escolas do $2^{o}$ Ciclo de Formação de Professores de Benguela, Angola.

\subsection{Metodología}

A nossa investigação assume um caráter exploratório, uma vez que assenta na recolha de opiniões dos professores nas Escolas do $2^{\circ}$ Ciclo de Formação de Professores de Benguela sobre a perceção que os mesmos têm acerca da liderança exercida pelos diretores.

Por se considerar a mais adequada ao trabalho realizado, optámos por uma metodologia Descritiva com um desenho não experimental, pelo método de questionário, em função da natureza quantitativa (questionário) do instrumento e tem as seguintes características:

- Quantitativa - porque se pretende explicar o fenómeno e pela possibilidade de uso do questionário.

- Aplicada - uma vez que decorrerá num contexto natural.

- Transversal - uma vez que é um estudo programado, onde os dados são recolhidos num determinado momento, de acordo com a seleção prévia dos professores e diretores.

É, pois, de acordo com os objetivos traçados para este trabalho, com o tipo de informação que importa recolher, e atendendo a um conjunto de métodos e técnicas de investigação existente na área das Ciências Sociais, que optámos pelo enfoque metodológico misto ou Descritivo, utilizando instrumentos de recolha de dados quantitativos. Assim, em consonância com os pressupostos e indicadores subjacentes ao enquadramento teórico que configurámos a investigação empírica.

\subsection{Instrumentos de recolha de dados}

O instrumento, aplicado tanto para professores como Para diretores, foi o questionário, tipo escala likert com 4 níveis de respostas $1=$ (discordo totalmente), $2=$ (discordo), $3=$ (concordo) e $4=($ concordo totalmente). Este seguiu um proceso de elaboração para tal fim, cumprindo com as características psicométricas exigidas, isto é, se realizou uma validação de conteúdo por juízo de peritos e calculou-se um índice de fiabilidade alto (alfa de cronbach 0,9). Quanto a sua estrutura, o questionário atende a diferentes dimensões: A- perfil pessoal e profissional, B- caracterização da escola, Cexploração das estratégias, mecanismos e formas de 
atuação mais utilizados pelos diretores das escolas de formação de profesores, D- estilos de liderança característicos desenvolvidos pelos diretores das escolas de formação de profesores e E- valorização da liderança diretiva nas escolas de formação de profesores.

\subsection{População e amostra}

$\mathrm{Na}$ provincia de Benguela, Angola, existem 12 escolas de formação de profesores entre públicas e comparticipadas. Importa ressaltar que a população é composta por 782 professores e 36 diretores das Escolas do $2^{\circ}$ Ciclo de Formação de Professores de Benguela. Foram distribuidos 425 questionários aos professores dos quais se obteve um retorno de 270 questionários respondidos, que correspondem a uma taxa de resposta de cerca de $64 \%$ e 36 questionários aos diretores tendo-se obtido um retorno de 15 questionários respondidos, que correspondem a uma taxa de resposta de cerca de $42 \%$. A amostra foi calculada na base de cerca de $54 \%$ da amostra geral dos professores e $100 \%$ da amostra geral dos diretores.

\section{RESULTADOS}

Os professores que participaram no estudo afirmaram em grande proporção que concordam $(49,9 \%)$ com o estilo de liderança dos diretores. Como se observa na tabela 2 , a percentagem varia de item a item, porém, em alguns itens a percentagem de concordância do estilo de liderança do diretor seja mais elevada que noutros. Em relação ao género encontrou-se uma grande diferença na amostra participante $70 \%$ são homens e $26,7 \%$ mulheres.

Igualmente, se encontrou uma percentagem alta $(22,1 \%)$ que indicou que os professores participantes do estudo discordam com o estilo de liderança do diretor, acrescido a $(9,8 \%)$ dos professores que discordam totalmente o que perfaz $(31,9 \%)$ da amostra participante que não concorda com o estilo de liderança do diretor.
Tabela 2. Estilos de liderança característicos desenvueltos pelos diretores das escolas de formação de professores

\begin{tabular}{lcccc}
\hline & $\begin{array}{c}\text { Discordo } \\
\text { totalmente }\end{array}$ & Discordo & Concordo & $\begin{array}{c}\text { Concordo } \\
\text { totalmente }\end{array}$ \\
\hline Item 31 & $7,8 \%$ & $18,5 \%$ & $53,7 \%$ & $20 \%$ \\
\hline Item 32 & $6,3 \%$ & $24,8 \%$ & $51,5 \%$ & $17,4 \%$ \\
\hline Item 33 & $5,9 \%$ & $20 \%$ & $54,4 \%$ & $19,6 \%$ \\
\hline Item 34 & $6,7 \%$ & $28,9 \%$ & $50,7 \%$ & $13,7 \%$ \\
\hline Item 35 & $5,9 \%$ & $22,6 \%$ & $57,4 \%$ & $14,1 \%$ \\
\hline Item 36 & $4,8 \%$ & $11,9 \%$ & $65,9 \%$ & $17,4 \%$ \\
\hline Item 37 & $3,4 \%$ & $7,8 \%$ & $56,3 \%$ & $32,2 \%$ \\
\hline Item 38 & $3,3 \%$ & $17,8 \%$ & $53,0 \%$ & $25,9 \%$ \\
\hline Item 39 & $4,1 \%$ & $12,2 \%$ & $59,6 \%$ & $24,1 \%$ \\
\hline Item 40 & $7,4 \%$ & $26,3 \%$ & $50,7 \%$ & $15,6 \%$ \\
\hline Item 41 & $4,1 \%$ & $23,7 \%$ & $60,4 \%$ & $11,9 \%$ \\
\hline Item 42 & $3,7 \%$ & $10,4 \%$ & $63,7 \%$ & $22,2 \%$ \\
\hline Item 43 & $8,1 \%$ & $21,1 \%$ & $47,4 \%$ & $23,3 \%$ \\
\hline Item 44 & $6,7 \%$ & $15,6 \%$ & $57 \%$ & $20,7 \%$ \\
\hline Item 45 & $3 \%$ & $21,5 \%$ & $57,8 \%$ & $17,8 \%$ \\
\hline Item 46 & $3 \%$ & $15,2 \%$ & $54,8 \%$ & $24,8 \%$ \\
\hline Item 47 & $4,4 \%$ & $10,7 \%$ & $60 \%$ & $24,8 \%$ \\
\hline Item 48 & $10,4 \%$ & $20,4 \%$ & $49,6 \%$ & $19,6 \%$ \\
\hline Item 49 & $9,3 \%$ & $28,1 \%$ & $50 \%$ & $12,6 \%$ \\
\hline Item 50 & $20 \%$ & $42,2 \%$ & $27,8 \%$ & $10 \%$ \\
\hline Item 51 & $10 \%$ & $31,5 \%$ & $47,8 \%$ & $10,7 \%$ \\
\hline Item 52 & $38,5 \%$ & $35,6 \%$ & $20 \%$ & $5,8 \%$ \\
\hline Item 53 & $31,9 \%$ & $40,7 \%$ & $20,7 \%$ & $6,7 \%$ \\
\hline Item 54 & $31,9 \%$ & $40,7 \%$ & $20,7 \%$ & $6,7 \%$ \\
\hline Item 55 & $26,7 \%$ & $41,5 \%$ & $23,3 \%$ & $8,5 \%$ \\
\hline Item 56 & $8,5 \%$ & $17 \%$ & $53 \%$ & $21,5 \%$ \\
\hline Item 57 & $4,8 \%$ & $17 \%$ & $55,6 \%$ & $23,3 \%$ \\
\hline Item 58 & $5,2 \%$ & $14,4 \%$ & $57 \%$ & $23,3 \%$ \\
\hline Item 59 & $3 \%$ & $10 \%$ & $62,6 \%$ & $24,4 \%$ \\
\hline Item 60 & $5,2 \%$ & $15,6 \%$ & $56,7 \%$ & $22,6 \%$ \\
\hline Total & $9,8 \%$ & $22,1 \%$ & $49,9 \%$ & $18,0 \%$ \\
\hline & & & & \\
\hline
\end{tabular}

A percentagem daqueles professores que estão de acordo com a valorização da liderança diretiva nas suas escolas é de $(56,4 \%)$ acrescido a $(26,7 \%)$ dos que concordam totalmente é superior em relação aos que discordam $(13,3 \%)$ acrescidos a $(3,5 \%)$ que discordam totalmente.

Quanto aos itens que compõem esta dimensão, tabela 3, observa-se que a percentagem de valorização varia de item a item. Em relação ao género da amostra participante, se observa o mesmo que na dimensão anterior maior percentagem de homens em relação as mulheres.

A totalidade de professores que concordam com o estilo de liderança do diretor em termos percentuais ascende em relação aqueles que não concordam. $\mathrm{O}$ mesmo verifica-se com a valorização da liderança diretiva nestas escolas.

A finalizar, acredita-se ser necessário munir os diretores por meio de formações de curta duração e constantes com conhecimentos sobre liderança de instituições educativas, pois o número de professores 
participantes do estudo que não concorda com o estilo de liderança do diretor, e não valoriza a liderança diretiva nestas escolas é bastante significativo $31,9 \%$ e $20,8 \%$ respetivamente.

Tabela 3. Valorização da liderança diretiva nas escolas de formação de professores.

\begin{tabular}{lcccc}
\hline & $\begin{array}{c}\text { Discordo } \\
\text { totalmente }\end{array}$ & Discordo & Concordo & $\begin{array}{c}\text { Concordo } \\
\text { totalmente }\end{array}$ \\
\hline Item 61 & $4,8 \%$ & $13 \%$ & $54,1 \%$ & $28,1 \%$ \\
\hline Item 62 & $2,6 \%$ & $10,7 \%$ & $59,3 \%$ & $27,4 \%$ \\
\hline Item 63 & $3 \%$ & $16,7 \%$ & $51,9 \%$ & $28,5 \%$ \\
\hline Item 64 & $2,6 \%$ & $10,7 \%$ & $53 \%$ & $33,7 \%$ \\
\hline Item 65 & $4,1 \%$ & $10 \%$ & $47,8 \%$ & $38,1 \%$ \\
\hline Item 66 & $3 \%$ & $19,6 \%$ & $55,9 \%$ & $21,5 \%$ \\
\hline Item 67 & $0,7 \%$ & $6,7 \%$ & $48,1 \%$ & $44,4 \%$ \\
\hline Item 68 & $4,1 \%$ & $14,8 \%$ & $51,9 \%$ & $29,3 \%$ \\
\hline Item 69 & $3 \%$ & $9,6 \%$ & $54,1 \%$ & $33,3 \%$ \\
\hline Item 70 & $2,6 \%$ & $12,2 \%$ & $62,2 \%$ & $23 \%$ \\
\hline Item 71 & $4,8 \%$ & $20,7 \%$ & $53 \%$ & $21,5 \%$ \\
\hline Item 72 & $3 \%$ & $11,9 \%$ & $58,1 \%$ & $27 \%$ \\
\hline Item 73 & $3,3 \%$ & $6,3 \%$ & $53,3 \%$ & $37 \%$ \\
\hline Item 74 & $6,3 \%$ & $21,9 \%$ & $46,3 \%$ & $25,6 \%$ \\
\hline Item 75 & $2,6 \%$ & $8,1 \%$ & $56,3 \%$ & $33 \%$ \\
\hline Item 76 & $4,1 \%$ & $7,4 \%$ & $53,7 \%$ & $34,8 \%$ \\
\hline Item 77 & $2 \%$ & $11 \%$ & $54 \%$ & $33 \%$ \\
\hline Item 78 & $3,7 \%$ & $11,1 \%$ & $52,2 \%$ & $33 \%$ \\
\hline Item 79 & $1,1 \%$ & $8,1 \%$ & $59,3 \%$ & $31,5 \%$ \\
\hline Item 80 & $2,2 \%$ & $10,4 \%$ & $66,7 \%$ & $20,7 \%$ \\
\hline Item 81 & $1,1 \%$ & $15,2 \%$ & $59,6 \%$ & $24,1 \%$ \\
\hline Item 82 & $4,1 \%$ & $10,4 \%$ & $65,2 \%$ & $20,4 \%$ \\
\hline Item 83 & $2,2 \%$ & $13,7 \%$ & $61,1 \%$ & $23 \%$ \\
\hline Item 84 & $4,1 \%$ & $17,0 \%$ & $55,2 \%$ & $23,7 \%$ \\
\hline Item 85 & $2,6 \%$ & $15,2 \%$ & $60,7 \%$ & $21,5 \%$ \\
\hline Item 86 & $3 \%$ & $5,9 \%$ & $66,3 \%$ & $24,8 \%$ \\
\hline Item 87 & $9,3 \%$ & $24,4 \%$ & $54,1 \%$ & $12,2 \%$ \\
\hline Item 88 & $7,4 \%$ & $24,4 \%$ & $57,4 \%$ & $10,7 \%$ \\
\hline Item 89 & $5,6 \%$ & $14,8 \%$ & $61,1 \%$ & $18,5 \%$ \\
\hline Item 90 & $3,7 \%$ & $17,8 \%$ & $61,1 \%$ & $17,4 \%$ \\
\hline Total & $3,5 \%$ & $13,3 \%$ & $56,4 \%$ & $26,7 \%$ \\
\hline & & & & \\
\hline
\end{tabular}

\section{DISCUSIÓN}

Os resultados obtidos mostram que em geral os professores concordam e aprovam o estilo de liderança dos diretores. Estudos prévios mostram que a liderança diretiva é uma das variáveis escolares que mais influencia no sucesso académico conjugado com o desempenho dos professores na sala de aulas (Avolio, 1997; Marfán, Muñoz e Weinstein, 2012; Mehdinezhad e Sardarzahi, 2016).

Tradicionalmente a liderança diretiva tem sido uma das grandes preocupações nas escolas que tem suposto um amplo leque de estudos e de linhas de investigação. Estas têm promovido valiosos aportes para o funcionamento da escola, destacando a importância da liderança na direção (Gómez, 2012;
Lorenzo, 1996, 1997, 1998; Murillo, 2006; Navareño, 2012; Oke, 2013); as dificuldades para seu acesso em função do género (Carmona e Padilla, 2009); sua vinculação com o êxito escolar e suas possibilidades de mudança para fazer frente as novas demandas socioeducativas (Álvarez, 2010; Aznar, Hinojo e Fernández, 2007; Coronel, Moreno e Padilla, 2002; Fernández e Gijón, 2012; Gairín e Armengol, 2003; Piña, 2014); a satisfação do cargo (Cuesta e Fernández, 2002; Hinojo, 2006); o rendimento académico do estudante e sua relação com o diretor.

Existe uma estreita relação entre liderança e poder que constitui uma peça fundamental na compreensão do funcionamento das organizações, (Lorenzo et al, 2011).

Investigações recentes evidenciam a existência de uma forte relação entre a liderança diretiva de qualidade em uma escola e o êxito de resultados de aprendizagem de seus estudantes (Elmore, 2010; Leithwood, 2006; Marfan, Weinstein e Muñoz, 2012; Zaitegui de Miguel, 2012).

\section{CONCLUSIONES}

Constatou-se que da amostra total de 270 professores o grupo de idade com maior representatividade é o dos professores com mais de 40 anos, maioritariamente do sexo masculino e de regime laboral efetivo.

Grande parte das escolas de formação de professores estudadas pertence ao núcleo urbano e o elenco de professores que nelas labutam são maioritariamente graduados com a licenciatura.

Quanto ao tipo de liderança predominante nestas escolas segundo a perceção dos professores participantes no estudo é a liderança participativa. Observando as percentagens obtidas da análise descritiva efetuada aos dados da investigação podemos concluir que a liderança colaborativa e a participativa são os tipos de liderança que mais sobressaem nestas instituições o que se encaixa perfeitamente no modelo ou estilo de liderança transformacional.

Este tipo, estilo ou modelo de liderança se identifica com atitudes, comportamentos e práticas que o definem e que são desenvolvidas pelos diretores das escolas de formação de professores de Benguela.

Sendo o modelo ou estilo de liderança transformacional, a que maior predominância apresenta, importa ressaltar as atitudes, comportamentos e práticas assumidas com frequência neste estilo de liderança que são: avaliar 
criticamente as crenças e pressupostos para ver se são apropriados, os líderes transformacionais expressam seus valores e crenças mais importantes, quando resolvem problemas tratam de vê-los de distintas formas, tratam de mostrar o futuro de modo otimista, fazem com que os demais se sintam orgulhosos de trabalhar com eles, falam com entusiasmo sobre as metas, consideram importante ter um objetivo claro no que se faz, pelo bem-estar do grupo vão além dos seus interesses, atuam de modo que ganham respeito dos demais, consideram as consequências morais e éticas nas decisões adotadas, se mostram confiáveis e seguros, enfatizam a importância de ter uma missão partilhada, expressam confiança em que se alcançam as metas, compartilham riscos nas decisões tomadas nos grupos de trabalho, quem trabalha com eles tem confiança nos seus juízos e decisões, motivam os demais a terem confiança em si mesmos, avaliam as consequências das decisões que tomam, tentam mostrar coerência entre o que dizem e o que fazem, ser um modelo a seguir para os demais, ajudam os outros a concentrarem-se nas metas que são alcançáveis, estimulam tolerância as diferenças de opiniões, tendem a comportar-se de modo a poder guiar os seus seguidores, expressam interesse aos demais pelos seus valiosos contributos, manifestam sua satisfação em trabalhar com os demais, os interessa conhecer as necessidades que tem o grupo de trabalho, expressam aos demais os benefícios que recebem quando são alcançadas as metas, sentem que os escutam com atenção.

Podemos concluir que os resultados obtidos da análise dos diferentes itens que compõem o questionário usado na investigação são positivos. Apesar de que devemos ter em conta de alguns aspetos negativos ressaltados pelos docentes participantes do estudo como por exemplo $12,2 \%$ destes afirmam que os diretores têm uma liderança autoritária.

As principais limitações do estudo são a falta de uma amostra mais representativa e aleatória que permita uma generalização dos resultados, a não inclusão de escolas de formação de professores do ensino privado e a existência de poucos estudos sobre liderança diretiva em Angola.

Portanto, para futuras investigações se pretende realizar um estudo mais amplo com uma amostra representativa e aleatória que inclua as escolas de formação de professores do ensino privadas.

Além disso, pretendemos realizar ações de formação para diretores a partir dos dados obtidos.

Agradecemos a todos os professores que participaram nesta investigação, assim como a colaboração das direções de escolas. Também agradecemos a Direção Provincial da Educação, Ciência e Tecnologia de Benguela pela autorização da recolha de dados nas diversas escolas de formação de professores da província.

\section{REFERENCIAS}

Álvarez, M. (2010). Dirección y éxito escolar. Una alternativa profesional a la dirección escolar. En C. Castilla Elena (Coord.). El liderazgo educativo: los equipos directivos en centros de primaria. Elementos básicos del éxito escolar (pp. 56-87).

Avolio B. (1997). The great leadership migration to Full Range Leadership development system. Kellogg Leadership Studies Project: Leadership Transformational, Working Papers. Academy of Leadership Press.

Aznar, I., Hinojo, F. J., e Fernández, F. D. (2007). Competencia, competencias profesionales y perfil profesional: retrato del perfil del psicopedagogo. Publicaciones, 37, 109116.

Begoña, S., Fernández, C., Martínez, M., e Roca, E. (2013). El liderazgo educativo en el contexto del centro escolar en XXXII Seminario interuniversitario teoria de la educación. Universidad de Cantabria.

Brugué, Q., Gallego, R., e Gonzalez, S. (2010). El lideratge en els centres educatius. Barcelona: Fundación Jaume Bofill.

Carmona, M., e Padilla, T. (2009). Barreras en el acceso a la dirección escolar: diferencias entre profesoras y directoras de centros de educación infantil y primaria. Revista Española de Orientación y Psicopedagogía, 20(1), 50-60.

Coronel, J.M., Moreno, E., e Padilla, M. T. (2002). La gestión y el liderazgo como procesos organizativos: Contribuciones y retos planteados desde una óptica de género. Revista de Educación, 327, 157-168.

Cuesta, J. D., e Fernández, S. (2002). Nivel de satisfacción de los cargos directivos de la Universidad de Granada en el desempeño de sus funciones. Enseñanza. Anuario Interuniversitario de Didáctica, 20.

Dans Álvarez de Sotomayor, I., e Muñoz, P.C. (2016). Las redes sociales como motivación para el aprendizaje: opinión de los docentes. Innoeduca, 2(1), 20-28. doi:10.20548/innoeduca.2016.v2i1.1041.

De Anquin, A., Burgos, M. E., e Soria, M.G. (2014). Contributors of a gender perspective in the training of professors. Journal for Educators, Teachers and Trainers (Jett), Special Issue "Gender and Citizenship", $16-25$.

Díaz Durán, Ma. D., e Martín Jaime, J.J. (2015). Evaluación del perfil competencial de alumnos universitarios respecto a la educación tecnológica. Innoeduca, 1(1), 17-24.

Gairín, J., e Armengol, C. (2003). Estrategias de formación para el cambio organizacional. Barcelona: Praxis.

Elmore, R. F. (2010). Mejorando la escuela desde la sala de clases. Santiago de Chile: Fundación Chile.

Fernández, M., e Gijón, J. (2012). Formación de profesionales basada en competencias. Journal for Educators, Teachers and Trainers (Jett), 3(1), 109-119.

Gámez, D. F., e Martín, M. D. G. (2016). Aprendizaje inverso en formación profesional: opiniones de los estudiantes. Innoeduca, 2(1), 29-37. 
Gómez, A. Ma . (2012). La sostenibilidad del liderazgo escolar en Andalucía a través de la modalidad formativa de tutela. Educatio Siglo XXI, 30(2), 423-444.

Hinojo Lucena, J. F. (2006). Percepción de los equipos directivos de los centros de Enseñanza Secundaria de Andalucía sobre la Formación Profesional reglada. Universidad de Granada. Inédita.

Hué, C. (2012). Liderazgo y coaching en la función directiva de los centros:Una metodología para la formación. Forum Aragon. 4-11.

Leithwood, K. (2006). ¿Cómo influye el liderazgo directivo en el aprendizaje de los estudiantes? Una perspectiva basada en la evidencia. Recuperado de http://ww2.educarchile.cl/UserFiles/P0001/File/PxL201 1_Files/Conferencia_Leithwood.pdf.

Lorenzo, M. (1996). El liderazgo pedagógico del director escolar: Situación y perspectivas, Jornadas de ADEME, UNED, Madrid.

Lorenzo, M. (1997).La función directiva en la década de los noventa: Qué se ha hecho y hacia dónde nos lleva el siglo XXI. En A. Medina (Coords.), El liderazgo en educación, Madrid: UNED.

Lorenzo, M. (1998). Liderazgo y participación en los centros educativos. Actas $V$ Congreso Interuniversitario de Organización de instituciones educativas, Madrid.

Lorenzo, M. (2004). La función de liderazgo de la dirección escolar: una competencia transversal. Enseñanza, 22, 193-211.

Lorenzo, M., Trujillo, J. M., e Morales, O. (2008). Los equipos directivos de Educación Primaria antes la integración de las TIC. Pixel-Bit. Revista de Medios y Educación, 3, 91-110.

Marfán, J., Muñoz, G., e Weinstein, J. (2012). Liderazgo educativo y prácticas docentes: Evidencia a partir del caso chileno.

Mehdinezhad, V., e Sardarzahi, Z. (2016). Leadership behaviors and its relation with Principals' management experience. NAER. 5(1), 11-16. doi:10.7821/naer.2016.1.133

Murillo, F. J. (2006). Una dirección escolar para el cambio: del liderazgo transformacional al liderazgo distribuido. REICE, 4(4e).

Navareño, P. (2012). La dirección de centros educativos en España. Liderazgo y gestión para la mejora escolar. En Avances en Supervisión Educativa, 17, 1-10.

Oke, A.E. (2013). Project Management Leadership Styles of Nigerian Construction Professionals. International Journal of Construction Project Management, 5(2), 159169.

País, F., Santos, C., e Pedro, L. (2016). The role of institutional leaderships in the SAPO Campus' adoption process. Digital Education Review, 29, 31-44.

Piña, R. (2014). Desarrollo de la formación permanente del profesorado en la provincia de Guadalajara. Un estudio de caso. Enseñanza e Teaching, 32(1), 141-159.

Podsakoff, P. M., MacKenzie, S. B., e Bommer, W. H. (1996). Transformational leader behaviors and substitutes for leadership as determinants of employee satisfaction, commitment, trust, and organizational citize. Journal of management, 22(2), 259-298.

Roca, E. (2011). El lideratge a l'aula. Escola Catalana, 468, 2832.

Sánchez Santa-Bárbara, E., e Rodríguez Fernández, A.(2010). 40 años de la Teoría del liderazgo situacional. Una Revisión. Revista Latinoamericana de Psicología, 42(1), 25-39.

Zaitegui de Miguel, N. (2012). Formación de Equipos Directivos. Coordinación y acompañamiento. En M.
Martín Bris e N. Zaitegui de Miguel (Eds.). El liderazgo educativo: proyectos de éxito escolar (pp. 11-60). Madrid: IFFIE, Ministerio de Educación. 